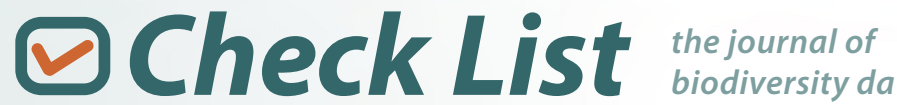

ఐ

\section{Apostolepis christineae Lema, 2002 (Serpentes: Xenodontinae: Elapomorphini): first record for Bolivia}

\author{
Omar Machado Entiauspe-Neto ${ }^{1 *}$ and Thales de Lema ${ }^{2}$ \\ 1 Instituto Federal de Educação, Ciência e Tecnologia Sul Rio Grandense, Campus Pelotas Visconde da Graça, Av. Engenheiro Ildefonso \\ Simões Lopes, 2791; 96060-290; Pelotas, Rio Grande do Sul, Brazil \\ 2 Southern Herpetology Office, Museu de Ciências e Tecnologia, Pontifícia Universidade Católica do Rio Grande do Sul, P.O. Box 1429, \\ Porto Alegre, Rio Grande do Sul, Brazil 90619-900 \\ * Corresponding author. E-mail: omarentiauspe@hotmail.com
}

\begin{abstract}
The fossorial snake Apostolepis christineae is an Elapomorphini species known only from a single specimen in Brazil. In this study, we report its occurrence to Bolivia, based on a male (BMNH 1907.10.31.62) from Puerto Suarez, Provincia German Busch, Departamento Santa Cruz, which was previously misidentified as Apostolepis vittata. This record extends the species distribution ca. $576 \mathrm{~km}$ west from its type locality. We also provide data on its morphological variation.
\end{abstract}

Keywords: Apostolepis christineae; Bolivia; geographical distribution; morphological variation

Apostolepis is the most diverse and distinct genus of Elapomorphini, including approximately 30 species, mainly diagnosed by their color patterns, with various degrees of intraspecific variation (Lema, 1993; Lema, 2002). Apostolepis christineae Lema, 2002 was described based on a single specimen from Serra das Araras, Cáceres, Mato Grosso, Brazil, housed in the Museu de Ciências e Tecnologia, Herpetological Collection (MCP/PUCRS). It's easily diagnosed from its most morphologically similar congener, A. vittata (Cope, 1887), by the presence of a flat and light colored snout, small and triangular supralabial blotch, five large and well-defined dorsal stripes, a black occiput extending to the gular region, compressed and round terminal spine, and a faint caudal blotch on subcaudals. Apostolepis christineae is also distinguished from most of its congeners by the presence of five supralabial scales, a character shared only with A. vittata, A. breviceps Harvey, Gonzales \& Scrocchi, 2001 and A. goiasensis Prado, 1942.

Years before the description of A. christineae, Harvey (1999) identified two specimens from Bolivia as Apostolepis vittata, but affirmed that they could belong to another species due to a few differences from the holotype of A. vittata. According to him, "The Bolivian specimens differ from the holotype [of $A$. vittata] in several noteworthy characteristics and the status of the Bolivian population should be reconsidered when larger samples become available. The most obvious difference is the vertebral stripe which is wide and extends to the tip of the tail in both Bolivian specimens."

While examining Apostolepis specimens from the British Museum of Natural History (BMNH), we came across one of the specimens cited by Harvey (1999), BMNH 1907.10.31.62, a male from Puerto Suarez, Provincia German Busch, Departamento Santa Cruz, Bolívia ( $18^{\circ} 58^{\prime} \mathrm{S}, 057^{\circ} 47^{\prime} 53^{\prime \prime} \mathrm{W} ; 103 \mathrm{~m}$ above sea level [a.s.l.]). After closer examination, it was revealed to be a specimen of Apostolepis christineae, the first record from Bolivia and outside Brazil.

We also have data on the pholidosis of the other specimen cited by Harvey (1999), a female from Río San Julian, Provincia Nuflo de Chaves, Departamento Santa Cruz, Bolívia ( $16^{\circ} 07^{\prime} 55^{\prime \prime} \mathrm{S}$, 062 $01^{\prime} 34^{\prime \prime}$ W; $496 \mathrm{~m}$ a.s.l.) housed in the Carnegie Museum (CM 2824), which matches A.christineae (Harvey, 1999: fig.1B, 4B). However, the last specimen was confiscated and destroyed by the Brazilian government in the past (Stephen P. Rogers, pers. comm.), and could not be directly examined by us now, only through data provided in Lema (2002).

The specimen BMNH 1907.10.31.62 (Figures 1 and 2) has a very projected and conical snout (while the holotype presents a flat snout), a white tail tip, the dark occiput extending to the gular region (as in the holotype), five dark dorsal stripes (ranging from between ( $1 / 2$ to 1 dorsal scales width), 243 ventral scales (240 in the holotype of A. christineae), 28 subcaudals (30 in the holotype), five supralabials, six infralabials, snout-vent length (SVL) $21.4 \mathrm{~cm}$ and tail length (TL) $19.0 \mathrm{~cm}$. The other specimen 


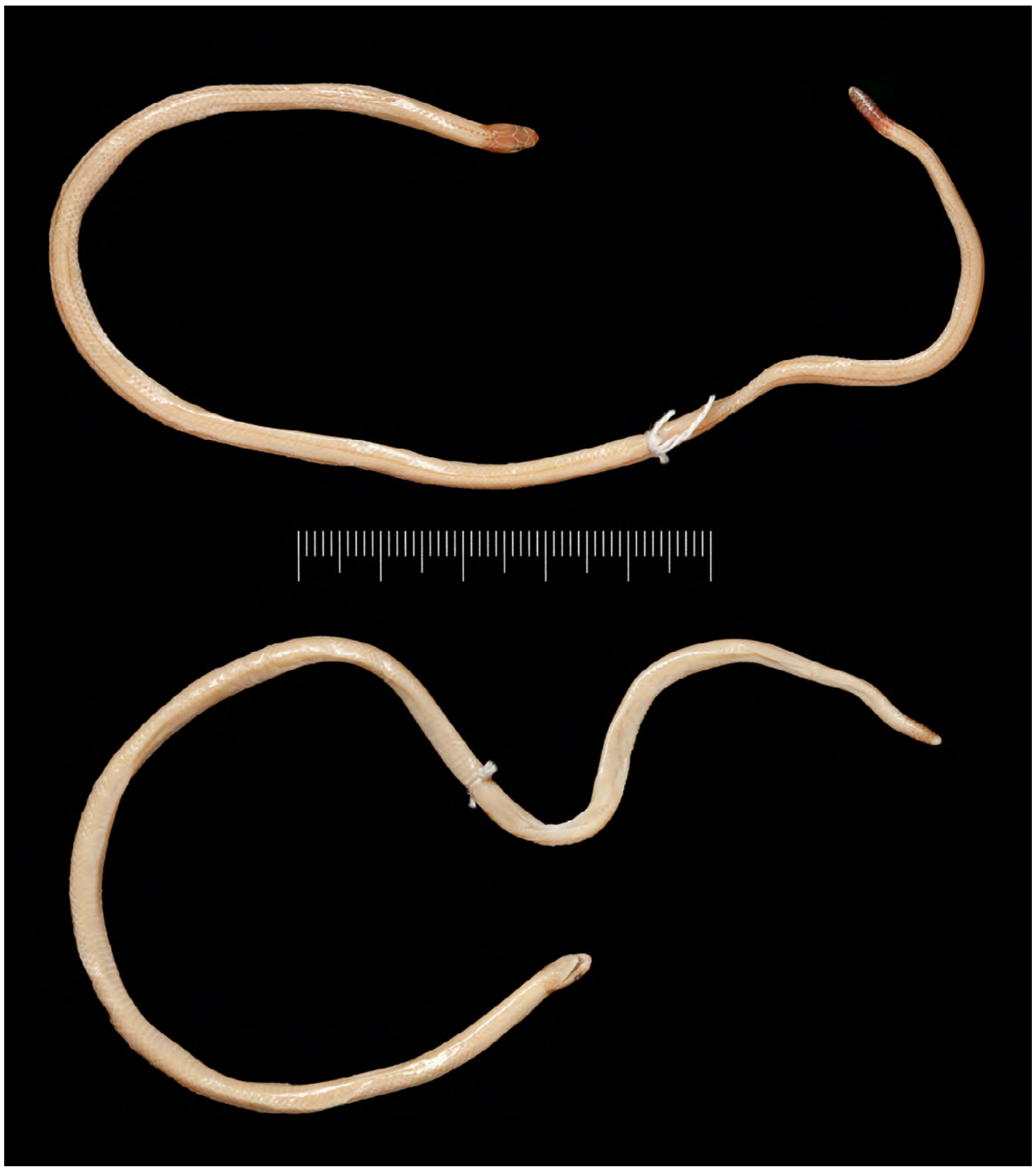

Figure 1. Dorsal and ventral view of the Apostolepis christineae specimen (BMNH 1907.10.31.62) from Puerto Suarez, Provincia German Busch, Departamento Santa Cruz, Bolivia. Photo credit: Patrick Campbell.

(CM 2824) was a female with a very projected and round snout, a white tail tip, five dark dorsal stripes, 228 ventral scales, 23 subcaudals, five supralabials, six infralabials, SVL $46.0 \mathrm{~cm}$ and TL $3.3 \mathrm{~cm}$. The meristic data of BMNH 1907.10.31.62 is similar to that of the holotype of A. christineae (MCP 12515), which has 30 subcaudals and 240 ventral scales. The comparison to CM 2824 (Lema 2002; Harvey 1999) allows us to confirm the identification as A. christineae.

This is the first record of Apostolepis christinae from outside Brazil, extending its distribution for $576 \mathrm{~km}$ west from its type locality, in Serra das Araras, Cáceres, Mato Grosso, the previously only known record for this species (Figure 3). The new Bolivian records are in the Chiquitano Dry Forests (Fund \& Hogan 2014), an ecoregion of the Tropical \& Subtropical Dry Broadleaf Forest biome (sensu Olson et al. 2001).

\section{ACKNOWLEDGEMENTS}

We thank Gláucia Maria Funk Pontes (MCP), for kindly permitting access to the collection and the examination of specimens under her care; Patrick Campbell (BMNH), for providing photographs of the A. christineae specimen. We also thank four anonymous reviewers and the copyeditor that provided great insights and thoughts in our paper. 


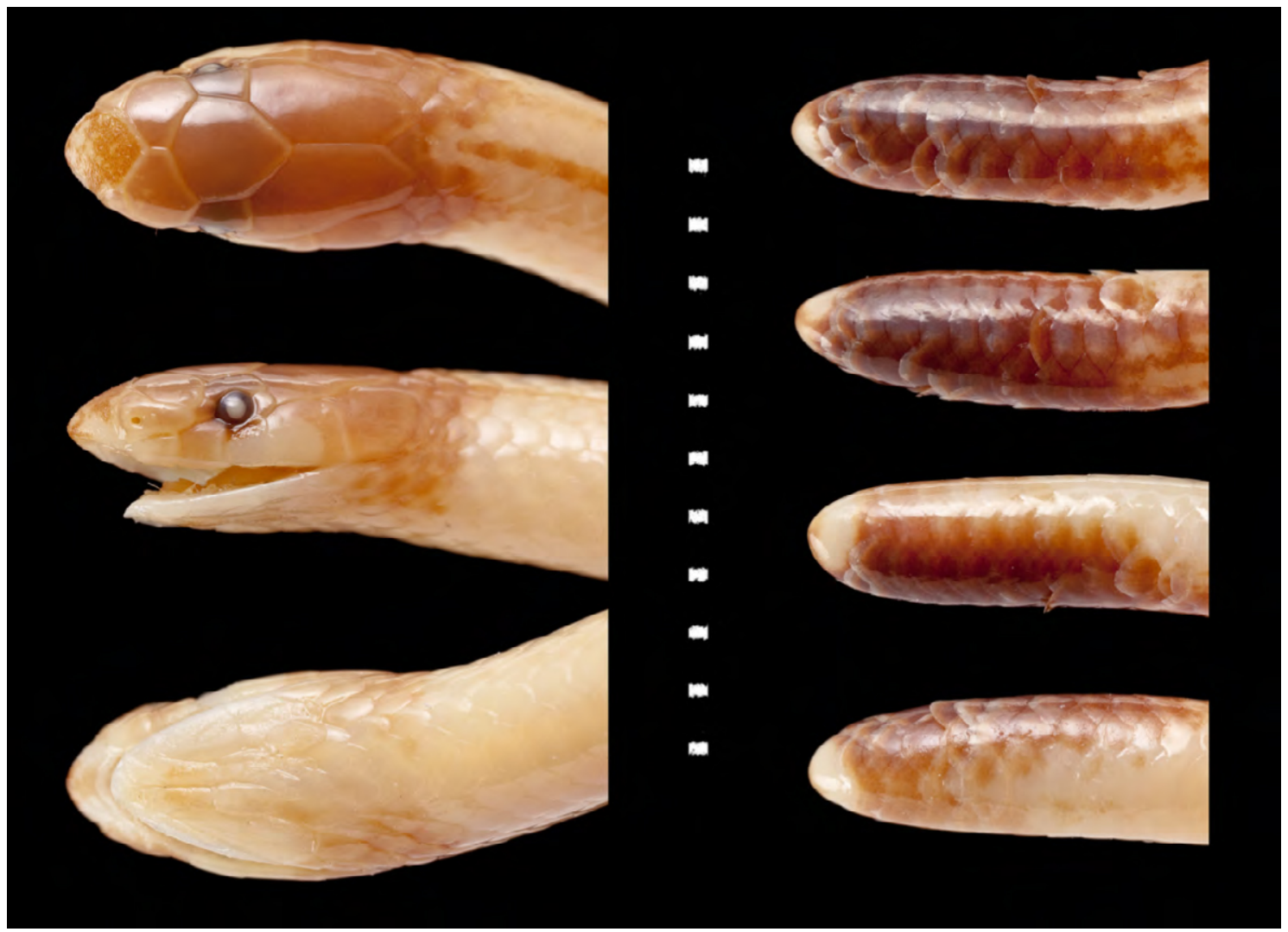

Figure 2. Head (Left) and tail (Right) views of the Apostolepis christineae specimen (BMNH 1907.10.31.62) from Puerto Suarez, Provincia German Busch, Departamento Santa Cruz, Bolivia. Photo credit: Patrick Campbell.

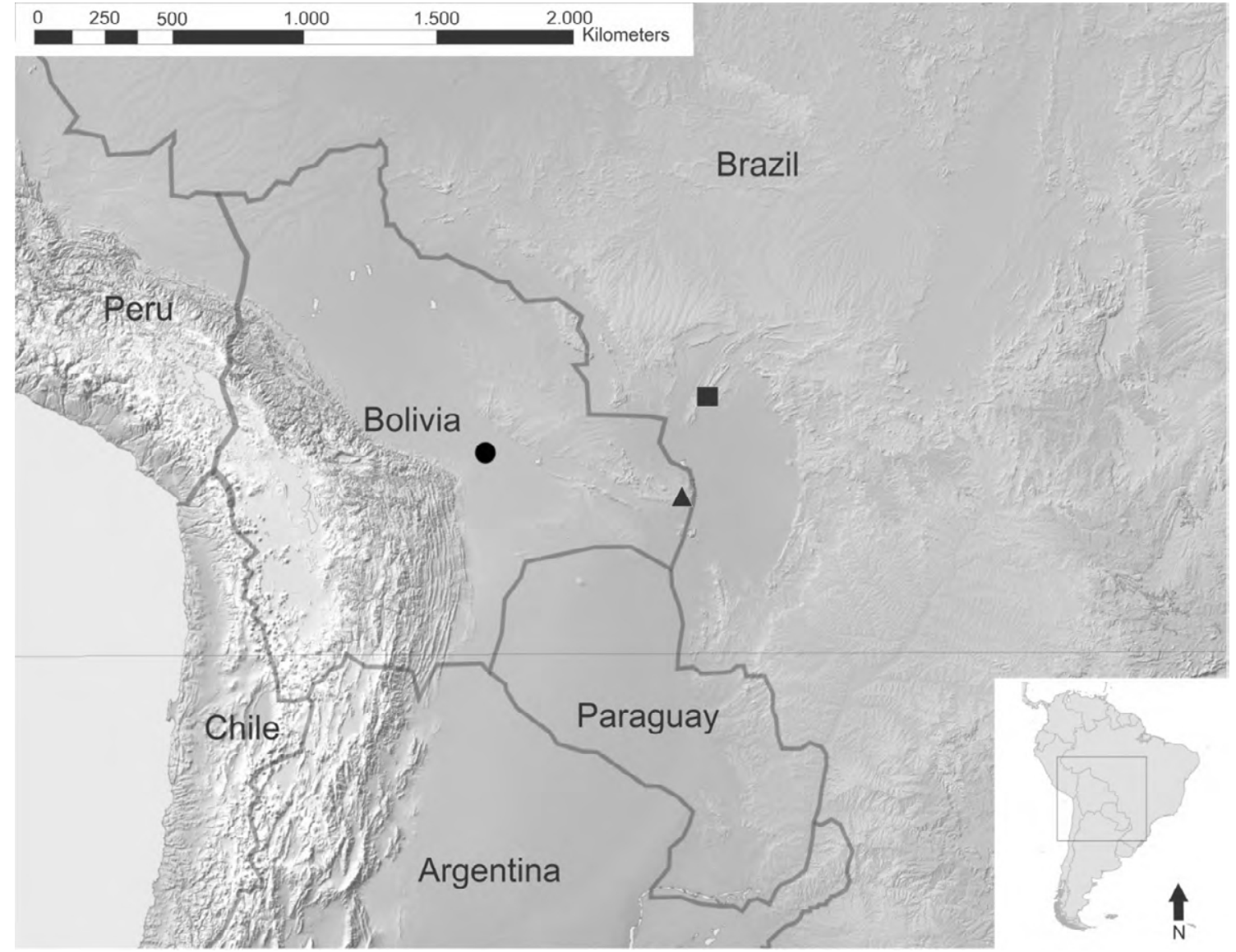

Figure 3. Distribution map of Apostolepis christineae: square: type locality (Serra das Araras, Mato Grosso, Brazil);, triangle: Puerto Suárez, Provincia German Busch, Departamento Santa Cruz, Bolivia; circle: Río San Julian, Provincia Ñuflo de Chaves, Departamento Santa Cruz, Bolivia (specimen not examined). 


\section{LITERATURE CITED}

Fund, W., and C. Hogan. 2014. Chiquitano dry forests. Accessed at http://www.eoearth.org/view/article/51cbed397896bb431f69oaac, 5 September 2015.

Harvey, M. B. 1999. Revision of Bolivian Apostolepis (Squamata: Colubridae). Copeia 1999 (2): 388-409. doi: 10.2307/1447485

Lema, T. 1993. Polimorfismo em Apostolepis dimidiata (Jan, 1862) com a invalidação de Apostolepis villaricae Lema, 1978 e Apostolepis barrioi Lema, 1978 (Serpentes: Colubridae: Xenodontinae: Elapomorphini). Acta Biológica Leopoldensia 15: 35-52.

Lema, T. 2002. Nova espécie de Apostolepis do grupo lineata do sudoeste do Brasil (Serpentes, Elapomorphinae). Facena 18: 41-52.

Olson, D. M., E. Dinerstein, E.D. Wikramanayake, N.D. Burgess, G.V.N. Powell, E.C. Underwood, J.A. D’Amico, I. Itoua, H.E. Strand, J.C.
Morrison, C.J. Loucks, S.T.F. Allnutt, T.H. Ricketts, Y. Kura, J.F. Lamoreux, W.W.Wettengel, P. Hedao andK.R. Kassem. 2001. Terrestrial ecoregions of the world: a new map of life on Earth. BioScience 51(11): 933-938. doi: 10.1641/ooo6-3568(2001)051[0933:TEOTWA] 2.o.CO;2

Author contributions: OME-N identified the specimen and wrote the manuscript; TDL also identified the specimen; took measurements, scale counts, and helped to write the manuscript.

Received: 6 July 2015

Accepted: 23 November 2015

Academic editor: Josué Anderson Rêgo Azevedo 